\title{
KINEMATIC MODEL CONSTRUCTION OF LOWER LIMB BASED ON LINKAGE MODEL
}

\section{Zsolt Tiba}

Department of Mechanical Engineering, Faculty of Engineering, University of Debrecen tiba@mfk.unideb.hu

\section{Abstract}

The human skeleton from mechanical point of view is a multi degree of freedom system supporting structure. Depending upon the fact whether the muscle groups are tightened, the supporting structure can be either determinate structure or statically indeterminate structure. The tightened muscles turn into the part of the supporting structure, the slack muscles make it possible that the structure operates as a mechanism. In this paper the simplified kinematics model of the lower limb and its analysis are presented.

Keywords: lower limb, kinematic model, biomechanical modeling

\section{Introduction}

The human lower limb made up of bones, joints and muscles is a multi degree of freedom system construction. The muscles yield a determinate construction in a tightened state. In this case all of the degrees of freedom of the construction are fastened by supporting. A slackened musculature limb is an unstable construction, acts as a mechanism, which moves due to the acting force and moment in the particular direction. Due to this construction which is unstable from mechanical point of view, a motion can be carried out. It can be achieved by tightening certain muscles and slacking others. Tightened muscles can be modelled by springs and act as rods in a construction.

The purpose of the paper is to subject the lower limb to kinematics analysis. On the base of fundamental mechanical theory I elaborated a very simple kinematics model of the lower limb. In the knowledge of basic principle, more sophisticated model can be constructed which takes more muscles and joints into account. It facilitates the more accurate modeling of operating of the lower limb. In the following chapters I outline the engineering fundamental concepts regarding the determinate and statically indeterminate structure, then I build up and analyze the kinematics model of the lower limb.

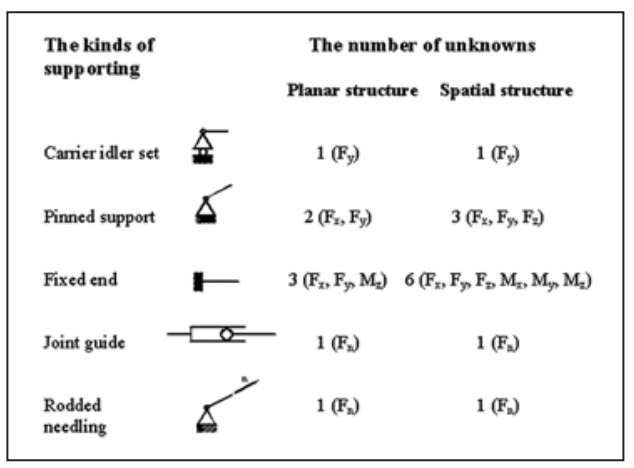

Table 1. Analysis of supporting

\section{Degree of freedom: $s$}

The number of the scalar data determining the position of the formation ${ }^{1}$ :

planar case spatial case

mass point: $2(\mathrm{x}, \mathrm{y}) \quad 3(\mathrm{x}, \mathrm{y}, \mathrm{z})$

figure: $\quad 3\left(\mathrm{x}, \mathrm{y}, \varphi_{z}\right) \quad 6\left(\mathrm{x}, \mathrm{y}, \mathrm{z}, \varphi_{x}, \varphi_{y}, \varphi_{z}\right)$ 
Determinate structure: $s=n_{\text {supporting }}$

s: number of the degree of freedom of the structure

$\mathrm{n}_{\text {supporting }}$ : number of the reactions of the structure

\section{Unstable structure: $\mathrm{s}>\mathrm{n}_{\text {supporting }}$}

Statically indeterminate structure: $\mathrm{s}<\mathrm{n}_{\text {supporting }}$

\section{Analysis of jointed structures}

The number of the equations: $3 \times$ the number of the rods

The number of unknowns: the number of reactions of the whole structure: depending upon the supporting, plus the number of reactions between the rods: $2 \times$ the number of pins ${ }^{2}$

(Number of pins: number of the rods connecting with the pin, minus 1 )

Application of the analysis in the case of structure containing 3 joints

E: the number of equations

$\mathrm{U}$ : the number of unknowns
$\mathrm{E}=2 \times 3=6$

$\mathrm{U}=2+2+2=6$

$\mathrm{E}=\mathrm{U}$, consequently all the reactions can be calculated

The equations of static state

- spatial: 6

- planar: 3 (generalized sum of $\mathrm{F}_{\mathrm{x}}, \mathrm{F}_{\mathrm{y}}, \mathrm{M}_{\mathrm{z}}$ are 0$), \sum F_{x}=0, \sum F_{y}=0, \sum M_{i}=0$

For the whole structure:

$$
M_{a}=0 \Rightarrow Y_{B} M_{b}=0 \Rightarrow Y_{A}
$$

For the rod 1

$M_{c}=0 \Rightarrow X_{A}$

$\sum X=0 \Rightarrow X_{12}$

$\sum Y=0 \Rightarrow X_{12}$

For the rod 2

$\sum X=0 \Rightarrow X_{B}$

Steps of the kinematic model construction of the lower limb

- substitution of the shinbone and thighbone by rods

- substitution of the ankle, knee, hip joint by joint

- consideration of muscles as springs and damping

- construction of the model as a mechanism

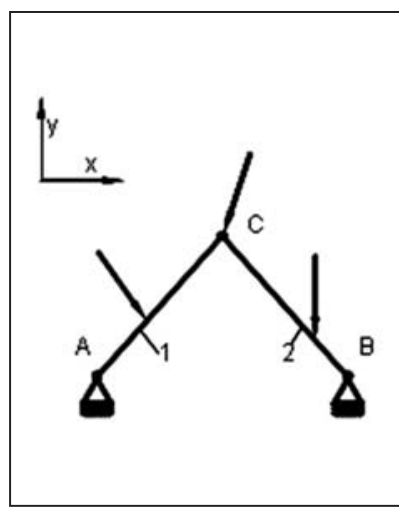

Figure 1. Structure containing 3 joints

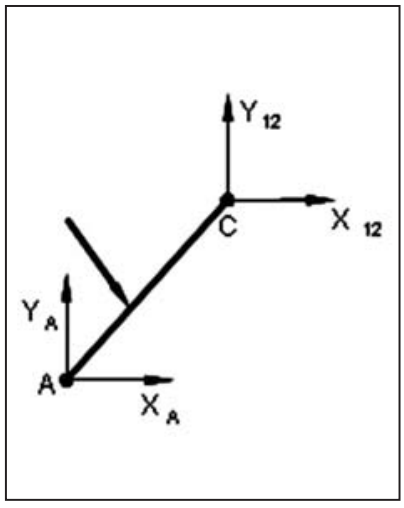

Figure 2. Analysis of rod 1

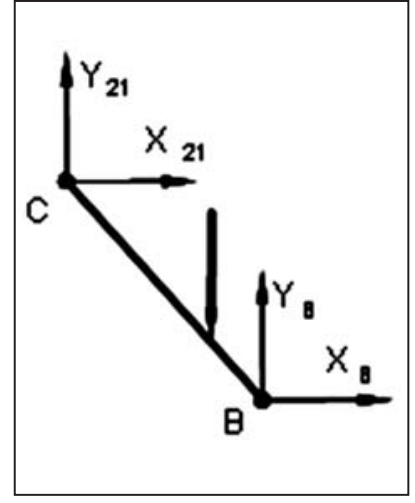

Figure 3. Analysis of rod 2 
Approximate kinematic model

of the lower limb

Further simplifications

- substitution of the muscle groups only by one spring

- consideration of tightened springs as rods

Applied designations in the Figure 4 and Figure 5:

Bones:

$$
\begin{aligned}
& 1-5, \sum 5 \\
& 1 \text { - fibula }+ \text { tibia } \\
& 2 \text { - ossa metatarsalia } \\
& 3 \text { - ossa tarsalia } \\
& 4 \text { - femur } \\
& 5 \text { - os coaxe }
\end{aligned}
$$

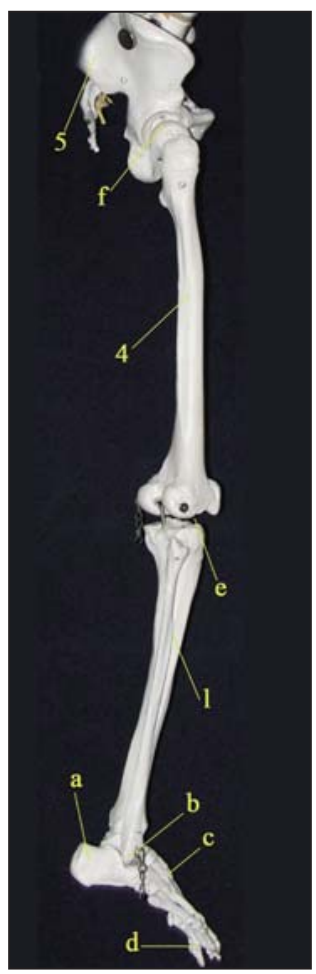

Figure 4. Build-up and analysis of the mechanism
Muscles, sinew:

$$
\begin{aligned}
& \alpha-\delta, \sum 4 \\
& \alpha-\text { Tendo calcaneus } \\
& \beta \text { - plantar muscles } \\
& \gamma-\text { musculus vastus } \\
& \delta \text { - musculus gluteus }
\end{aligned}
$$

Joints connecting bones:

$$
\begin{aligned}
& \text { a-f, } \sum 6 \\
& \text { a - Chopart's joint } \\
& \text { b - ankle joint } \\
& \text { c - tarsal joint } \\
& \text { d - metatarsophlengeal joint } \\
& \text { e - knee joint } \\
& \text { f - hip joint }
\end{aligned}
$$

Joints fastening muscles to bone: $\mathrm{g}-\mathrm{n}, \sum 8$

Number of the rods (bones and muscles): 9 (It provides $9 \times 3=27$ mechanical equations)
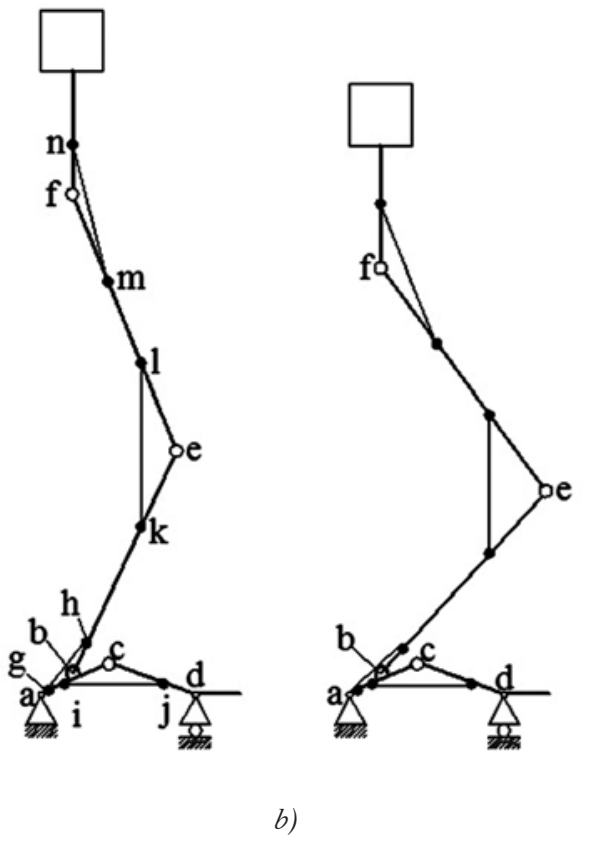

Figure 5. Positions of the mechanism during the step

(a) muscles are flabby,

(b) muscles are tightened 
Number of joints (between bones and Conclusion

between bone and muscle): $5+8=13$

(It provides $13 \times 2=26$ reaction forces)

In possession of the expertise relating to the kinematics modeling of lower limb and limb, it becomes possible to design such artificial limbs which motion form is similar to the original one. The loads and forces acting on the skeleton made statically determinate by Equations $=9 \times 3=27$

Unknowns $=13 \times 2+1=27$, consequently all the reactions can be calculated. tightened muscles can be calculated, in this way the stressing of artificial limbs can be carried out.

\section{REFERENCES}

1. Ugural A. Mechanical Design. New York: McGraw-Hill; 2004.
2. Shigley J, Mischke C, Budynas R. Mechanical Engineering Design. New York: McGraw-Hill; 2004.

\section{Dr. Zsolt Tiba}

Department of Mechanical Engineering, Faculty of Engineering, University of Debrecen H-4028 Debrecen, Ótemetô u. 2-4.

Tel.: (+36) 52 422-088 